\begin{tabular}{|c|c|c|c|c|c|c|}
\hline \multirow{4}{*}{ Impact Factor: } & ISRA (India) & $=4.971$ & SIS (USA) & $=0.912$ & ICV (Poland) & $=6.630$ \\
\hline & ISI (Dubai, UAE & $=0.829$ & РИНЦ (Russia) & $=0.126$ & PIF (India) & $=1.940$ \\
\hline & GIF (Australia) & $=0.564$ & ESJI (KZ) & $=8.716$ & IBI (India) & $=4.260$ \\
\hline & JIF & $=1.500$ & SJIF (Morocco) & $=5.667$ & OAJI (USA) & $=0.350$ \\
\hline
\end{tabular}

\section{SOI: 1.1/TAS DOI: $10.15863 /$ TAS \\ International Scientific Journal Theoretical \& Applied Science}

p-ISSN: 2308-4944 (print) e-ISSN: 2409-0085 (online)

Year: $2020 \quad$ Issue: 03 Volume: 83

Published: $30.03 .2020 \quad$ http://T-Science.org
QR - Issue

QR - Article

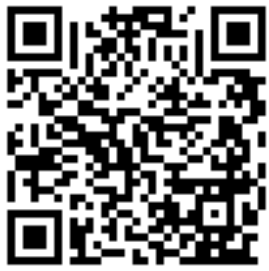

I. Charkviani

Akaki Tsereteli State University Ph.D., Georgia, Kutaisi

N.N. Tkhelidze

Akaki Tsereteli State University Ph.D., Engineering Sciences PhD. Associate Professor, Head of Department Design and Technology

M. G. Grdzelidze

Akaki Tsereteli State University Ph.D., Professor of the Department "Design and Technology", Dean of Engineering-Technological Faculty

Georgia, Kutaisi

\title{
STUDYING THE PACKAGE OF MATERIALS USED IN MANUFACTURE OF RACHA DANCING SUIT
}

Abstract: Traditional clothing is an important part of the material culture of the people. It reflects its character, the level of spiritual and material culture, and age-old traditions. In the preservation and promotion of the national costume, an important role played by choreography and dancing suits, whose comfort in wear is due to materials used.

Key words: traditional clothing, clothing package, package thickness.

Language: Russian

Citation: Charkviani, I., Tkhelidze, N. N., \& Grdzelidze, M. G. (2020). Studying the package of materials used in manufacture of racha dancing suit. ISJ Theoretical \& Applied Science, 03 (83), 333-336.

Soi: http://s-o-i.org/1.1/TAS-03-83-61 Doi: crossef https://dx.doi.org/10.15863/TAS.2020.03.83.61

Scopus ASCC: 2209.

\section{ИССЛЕДОВАНИЕ ПАКЕТА МАТЕРИАЛОВ РАЧИНСКОГО ТАНЦЕВАЛЬНОГО КОСТЮМА}

Аннотация: Традиционная одежда является важным элементом материальной культуры народа. В ней отражаются его характер, уровень духовной и материальной культуры, многовековые традиции. В деле сохранения и популяризачии национального костюма важную роль играет хореография и танцевальные костюмы, удобность и комфортность которых обусловлено используемыми материалами.

Ключевые слова: традиционная одежда, пакет одежды, толщина пакета.

\section{Введение}

Народный танец и народный костюм - это составляющие одного целого. В воплощении народного танца большое значение имеют сценические костюмы, которые создаются на основе народного. Разнообразие традиционной одежды и танцевальных стилей во многом обусловлено разнообразием этнических групп внутри страны. Грузия очень выдающаяся страна в этом отношении. На западе и востоке, в горах и равнинах каждий этнический уголок Грузии имел свои традиции, образ жизни, костюмы и танцы, которые отражены в современных хореографических представлениях.

Следует отметить, что современные костюмы более или менее приближены к традиционной одежде, чего нельзя сказать о танцевальном костюме прекраснейшего, горного 


\begin{tabular}{|c|c|c|c|c|c|c|}
\hline \multirow{4}{*}{ Impact Factor: } & ISRA (India) & $=4.971$ & SIS (USA) & $=0.912$ & ICV (Poland) & $=6.630$ \\
\hline & ISI (Dubai, UAE & $=0.829$ & РИНЦ (Russia & $=0.126$ & PIF (India) & $=1.940$ \\
\hline & GIF (Australia) & $=0.564$ & ESJI (KZ) & $=8.716$ & IBI (India) & $=4.260$ \\
\hline & JIF & $=1.500$ & SJIF (Morocce & $=5.667$ & OAJI (USA) & $=0.350$ \\
\hline
\end{tabular}

этнического уголька Грузии - Рача. Женский танцевальный костюм в корне отличается от традиционной одежды этого уголька $[1 ; 2]$.

Целью исследования является разработка танцевального костюма на основе изучения женского традиционного костюма Рача, исследование и оптимизация пакета материалов. Для изготовления танцевального костюма были выбраны те же материалы, что и в традиционном костюме и были определены структурные показатели и физические свойства используемых материалов (хлопчатобумажные и шелковые ткани), с использованием стандартных методов [3; 4].

Для определения общего теплового сопротивления пакета одежды, которое необходимо для комфорта и удобства танцовщицы, во время эксплуатации костюма, вся поверхность тела человека была разделена на отдельные области и структура пакета одежды определялась соответственно.

Следует отметить, что воздушный слой между телом человека и одеждой, а также слоями одежды оказывает большое и существенное влияние на теплозащитность и воздухопроницаемость одежды. В танцевальном костюме средний слой воздуха варьируется от 115 мм и зависит от материала и конструкции одежды, условий работы танцора $[5 ; 6 ; 7 ; 8]$. Схематическое изображение пакета одежды на участке плеча и предплечья показано на рис. 1.

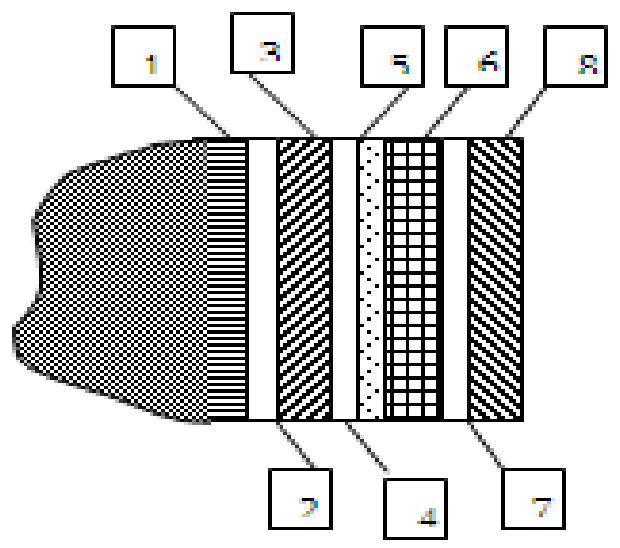

Рис. 1. Схема пакета одежды на плече и области предплечья: 1 холст; 2; 4; 7-слой воздуха; Сатин-3; 5клеевые прокладки; Сатин-6; 8- Миткаль

Табл. 1. Структура пакета одежды на участке тела

\begin{tabular}{|c|c|c|c|}
\hline состав & $\begin{array}{c}\text { Толщина } \\
\text { элементов } \\
\text { пакета, м } \\
\end{array}$ & $\begin{array}{c}\text { Коэффициент } \\
\text { теплопроводности } \lambda \\
\text { вт } / \mathrm{M}^{2}{ }^{\circ} \mathrm{C} \\
\end{array}$ & $\begin{array}{c}\text { Тепловое } \\
\text { сопротивление } \\
\mathrm{M}^{2} \cdot{ }^{\circ} \mathrm{C} / \mathrm{BT},\end{array}$ \\
\hline Средний слой воздуха & 0.001 & 0,01 & 0,1 \\
\hline Хлопок & 0,0008 & 0,041 & 0,119 \\
\hline Средний слой воздуха & 0,001 & 0,01 & 0,100 \\
\hline Хлопок & 0,0009 & 0,041 & 0,120 \\
\hline Средний слой воздуха & 0,0015 & 0,044 & 0,113 \\
\hline Сатин & 0,0010 & 0,042 & 0,130 \\
\hline Средний слой воздуха & 0,0015 & 0,019 & 0,103 \\
\hline Сатин & 0,0009 & 0,045 & 0,138 \\
\hline
\end{tabular}

Табл. 2. Структура пакета на плече и предплечья

\begin{tabular}{|c|c|c|c|}
\hline состав & $\begin{array}{c}\text { Толщина } \\
\text { элементов } \\
\text { пакета, м }\end{array}$ & $\begin{array}{c}\text { Коэффициент } \\
\text { теплопроводности } \lambda \\
\text { вт } / \mathrm{M}^{2}{ }^{\circ} \mathrm{C}\end{array}$ & $\begin{array}{c}\text { Тепловое } \\
\text { сопротивление } \\
\mathrm{M}^{2} \cdot{ }^{\circ} \mathrm{C} / \mathrm{BT},\end{array}$ \\
\hline Средний слой воздуха & 0,001 & 0,01 & 0,10 \\
\hline Хлопок & 0,0008 & 0,046 & 0,120 \\
\hline Средний слой воздуха & 0,001 & 0,01 & 0,1 \\
\hline Сатин & 0,0009 & 0,042 & 0,013 \\
\hline Средний слой воздуха & 0,0015 & 0,044 & 0,101 \\
\hline
\end{tabular}




\begin{tabular}{|c|c|c|c|c|c|c|}
\hline \multirow{4}{*}{ Impact Factor: } & ISRA (India) & $=4.971$ & SIS (USA) & $=0.912$ & ICV (Poland) & $=6.630$ \\
\hline & ISI (Dubai, UAE & $=0.829$ & РИНЦ (Russia) & $=0.126$ & PIF (India) & $=1.940$ \\
\hline & GIF (Australia) & $=0.564$ & ESJI (KZ) & $=8.716$ & IBI (India) & $=4.260$ \\
\hline & JIF & $=1.500$ & SJIF (Morocco) & $=5.667$ & OAJI (USA) & $=0.350$ \\
\hline
\end{tabular}

\begin{tabular}{|l|c|c|c|}
\hline Клеевая прокладка & 0,0005 & 0,04 & 0,375 \\
\hline Сатин & 0,0009 & 0,05 & 0,130 \\
\hline Средний слой воздуха & 0,0015 & 0,019 & 0,105 \\
\hline Миткаль & 0,0002 & 0,052 & 0,009 \\
\hline
\end{tabular}

Табл. 3. Структура пакета на бедре

\begin{tabular}{|c|c|c|c|}
\hline состав & $\begin{array}{c}\text { Толщина } \\
\text { элементов пакета, } \\
\text { м }\end{array}$ & $\begin{array}{c}\text { Коэффициент } \\
\text { теплопроводности } \lambda \\
\text { вТ }\left(\mathrm{M}^{2}{ }^{\circ} \mathrm{C}\right)\end{array}$ & $\begin{array}{c}\text { Тепловое } \\
\text { сопротивление } \\
\mathrm{M}^{2} \cdot{ }^{\circ} \mathrm{C} / \mathrm{BT},\end{array}$ \\
\hline Средний слой воздуха & 0.001 & 0,010 & 0,1 \\
\hline Миткаль & 0,0008 & 0,046 & 0,0120 \\
\hline Средний слой воздуха & 0,001 & 0,010 & 0,1 \\
\hline Миткаль & 0,0009 & 0,042 & 0,0130 \\
\hline Средний слой воздуха & 0,0015 & 0,044 & 0,1 \\
\hline Сатин & 0,0010 & 0,042 & 0,143 \\
\hline Средний слой воздуха & 0,001 & 0,01 & 0,01 \\
\hline Сатин & 0,0009 & 0,045 & 0,138 \\
\hline
\end{tabular}

Структура пакета материалов Рачинского танцевального костюма на разных участках тела показаны на рис. 2.
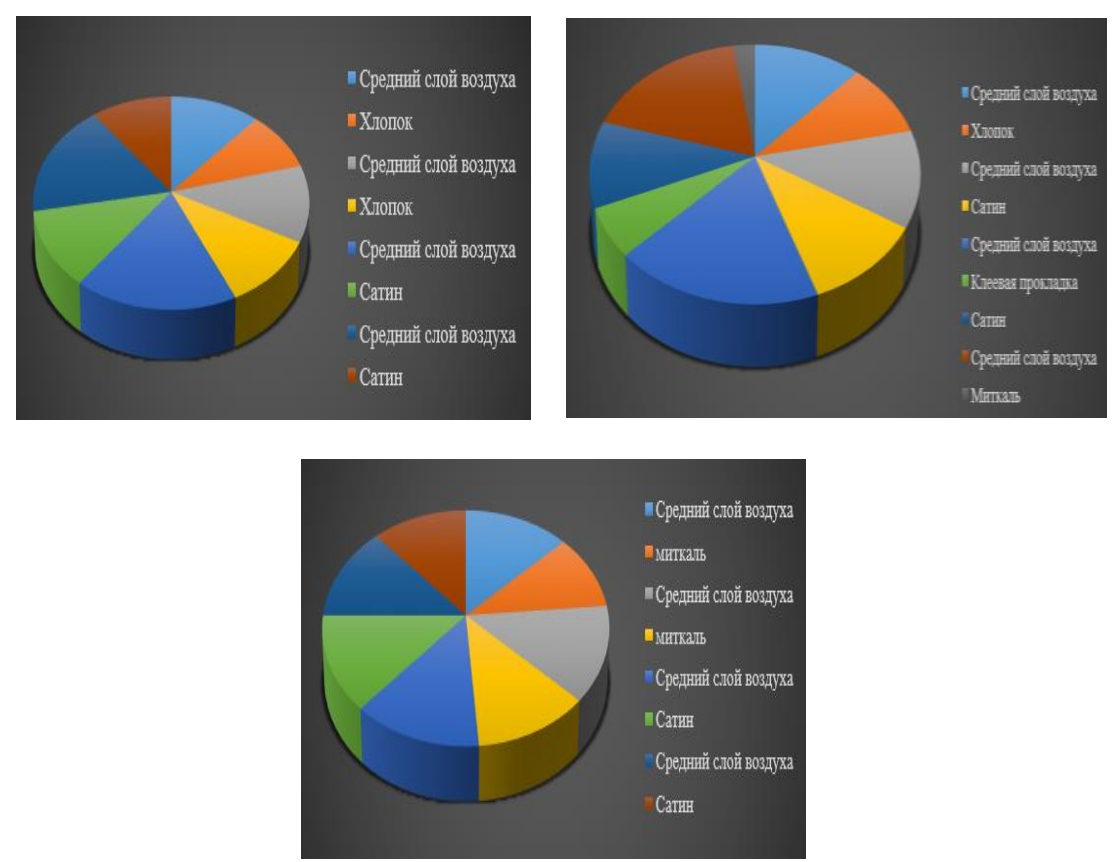

Рис. 2. Структура пакета материалов рачинского танцевального костюма на участке:

а) тела; б) плеча и предплечья; в) бедра.

\section{Заключение.}

Термостойкость текстильных изделий существенно зависит от их толщины, и эта зависимость является линейной $[9 ; 10]$. Исследования показали, что толщина пакета материалов традиционной одежды женщин на участках тела, плеча и предплечья бедра отличаются от толщины пакета материалов танцевального костюма на соответствующих участках и значительно больше. Это вызвано, прежде всего многослойностью пакета. Многослойность пакета определяет также вес одежды- 2,100 кг, в то же время общее тепловое сопротивление в областях тела, плеча, предплечья и бедер составляет $0,25-0,284$ м $2^{\circ} \mathrm{C} /$ вт. Соответственно, тепло, выделяемое во время танца, легко распространяется от поверхности тела к окружающей среде, таким образом защищая тело от перегрева и обеспечивая комфортное состояние танцора за время танца. 


\begin{tabular}{|c|c|c|c|c|c|c|}
\hline \multirow{4}{*}{ Impact Factor: } & ISRA (India) & $=4.971$ & SIS (USA) & $=0.912$ & ICV (Poland) & $=6.630$ \\
\hline & ISI (Dubai, UAE & $=0.829$ & РИНЦ (Russia & $=0.126$ & PIF (India) & $=1.940$ \\
\hline & GIF (Australia) & $=0.564$ & ESJI (KZ) & $=8.716$ & IBI (India) & $=4.260$ \\
\hline & JIF & $=1.500$ & SJIF (Morocce & $=5.667$ & OAJI (USA) & $=0.350$ \\
\hline
\end{tabular}

\section{References:}

1. Makalatija, S. (1987). “Gornaja Racha”. (p.98). Tbilisi.

2. Brailashvili, N. (1987). Jetnograficheskie zarisovki. (p.267). Tbilisi.

3. (n.d.). 8th International Conference «Science and practice: a new level of integration in the modern world» - thermal properties of materials of traditional clothing - rach. USA, San Francisco, California.

4. Kolesnikov, P.A. (1965). Teplozashhitnye svojstva materialov odezhdy. (p.340). Moscow: Ljogkaja industrija.

5. Buzov, B.A. (2004). materialovedenie $v$ proizvodstve izdelii ljogkoj promyshlennosti (shvejnoe proizvodstvo), uchebnik dlja studenotov vysshih uchebn. Zavedenii. (p.448). Moscow: Izdatel'skij centr "Akademija".

6. Mikova, E.V. (n.d.). teplomasoobmennye svojstva materialov i paketov teplozashhitnoj odezhdy. Shvejnaja promyshlennost'. 200. №6. pp. 7-9.

7. Stel'mashenko, V.I. (2010). Materialy dlja odezhdy $i$ konfekcionirovanie. (p.320). Izdatel'skij centr "Akademija".

8. Orlenko, L.V. (2006). Konfekcionirovanie materialov dlja odezhdy. (p.288). Moscow: FORUM-INFA-M.

9. (2010). Gigiena odezhdy. Raschjot paketa materialov dlja shvejnogo izdelija bytovogo naznachenija Metodicheskie ukazanija $\mathrm{k}$ laboratornym rabotam dlja studentov special'nosti "Konstruirovanie shvejnyh izdelii. Saratov, p.11.

10. Kulokov, B.P. (2006). Gigiena, komfortnost' $i$ bezopasnost' odezhdy. Uchebn.Posobie. (p.256). Ivanovo: IGTA. 